\title{
Socio-economic Determinants of Maternal Healthcare Utilization in Addis Ababa
}

\author{
Muluneh Yigzaw Mossie ( $\nabla$ yigzawm@gmail.com ) \\ University of South Africa https://orcid.org/0000-0002-6445-8323 \\ Peter Sandy \\ University of South Africa
}

\section{Research}

Keywords: Universal Coverage, Antenatal Care, Childbirth, Post-partum Care, Access to Healthcare, Social Determinants

Posted Date: May 22nd, 2020

DOI: https://doi.org/10.21203/rs.3.rs-29741/v1

License: (1) This work is licensed under a Creative Commons Attribution 4.0 International License. Read Full License 


\section{Abstract \\ Background}

Despite progresses over the last two decades, Ethiopia is one of the countries in the world with significant number of maternal deaths and service use for antenatal, labour and childbirth is low. This study intended to identify the underlying causes of low coverage of maternal health services in Addis Ababa.

\section{Methods}

We conducted a comparative cross-sectional study in Addis Ababa in July 2017. A three stage sampling technique was applied to select the study population. The first step was to select study Ketenas using simple random sampling. The villages within the Ketenas were then identified, which led to the second stage of the sampling process. In the third stage, a fixed number of 20 households per village were selected with an equal probability random selection from the newly created household listing. All women aged 18-49 years who gave birth one year preceding the date of data collection were then invited to a face-to-face interview. Both multiple linear regression and logistic regression were applied to estimate crude and adjusted associations.

\section{Results}

Less than $45.0 \%$ of women from the poorest households received all the recommended ANC contacts at the right time, while $71.4 \%$ of women from richest households received all the recommended contacts at the right time. The majority of women from poorest households gave birth at health centres $(66.2 \%)$, followed by public hospitals (30.9\%). The largest proportion of women from richest households gave birth at private hospitals (46.1\%), followed by public hospitals (16.1\%). Meanwhile, only $52.5 \%$ of women with primary education had all the recommended ANC contacts, while $78.5 \%$ of women who completed tertiary education had all the recommended ANC contacts $(p<0.001)$. Women from richest households were less likely to face multiple barriers to use maternal health services as compared to women from poorest households $(\mathrm{OR}=0.57, \mathrm{p}=0.032)$.

\section{Conclusion}

There is a huge inequality in maternal healthcare coverage in Addis Ababa. To achieve universal maternal health coverage, affordability of the service is not adequate although it is one of the requirements. Other underlining social determinants deserve the attention of policy makers and program designers.

\section{Introduction}


Since the establishment of the United Nations in 1945, the world has strived to ensure access to healthcare for all populations regardless of the place where they are living. Despite this effort, however, access to healthcare is hitherto a major challenge for populations of various socioeconomic groups [14]. Women from disadvantaged communities often experience problems in accessing healthcare services, including lifesaving interventions $[5,6]$. As empirical evidence reveals, there is widespread inequality in accessing health services during pregnancy and childbirth between women from affluent background and those from poor socio-economic groups [7, 8]. The gap in accessing health services between these two categories of women, poor and rich, is widening over time [9]. This probably explains the high mortality rate in the former category, poor women.

The United Nations identified universal health coverage as one of the targets under the Sustainable Development Goal (SDG) three; “Ensure healthy lives and promote well-being for all at all ages” [10]. Universal health coverage is a broad initiative with the goal of ensuring that people are offered the health services they need [11]. However, availing all services at a time to every person is not practical for most low-income countries [12]. Thus, low-income countries are required to examine the health problems of their populations. Doing so will enable them to identify appropriate and priority interventions that need to be addressed first. Consequently, less priority services will be covered after making sure that the high priority services are reaching every population group without significant financial hardship [13].

The World Health Organization (WHO) developed a guidance to prioritize interventions that need universal coverage [12]. Maternal health related interventions are among the first priority areas that require universal coverage for all populations [14]. Maternal health has been part of the health related SDG targets as well. The global community aims to bring maternal mortality ratio below 70 per 100000 live births and newborn mortality rate to 12 per 1000 live births in all countries by 2030 [10].

Ethiopia has built a significant number of health facilities and, at the same time, a huge number of midlevel healthcare providers has been trained and deployed across all districts over the last two decades to scale up primary healthcare, including delivery of maternal health services [15]. The goal is to provide basic curative, preventive and promotive services to the population of Ethiopia even in remote rural areas where health services are rarely found, thereby to achieve universal coverage to priority health services.

Despite such huge efforts, Ethiopia is still one of the countries in the world with a significant number of maternal and child deaths and service use for antenatal, labour and childbirth is low [16]. The maternal mortality ratio and the neonatal mortality rate are still high, and these are estimated at 412 per 100000 live births and 29 per 1000 live births respectively [16]. Moreover, Ethiopia is among the countries with considerable socio-economic related inequalities in the coverage of maternal and newborn health interventions [17]. The state offers most interventions related to maternal and newborn health free of charge at primary healthcare level but substantial number of women still choose to give birth at their home, and the antenatal care coverage is the lowest compared with some of the countries in SubSaharan Africa [7]. 
It is imperative, therefore, to investigate the multiple factors responsible for this low level utilization of maternal health services and unacceptably high maternal deaths. The systematic and comprehensive investigation that includes the underlining causes, which is also known as the 'causes of causes' are important for policy making and to design effective strategies. Therefore, this study intended to identify the underlying causes of low coverage of maternal health services in Addis Ababa

\section{Methods}

\section{Study Setting}

Addis Ababa is the capital of Ethiopia with a projected population of over five million in 2020. The Central statistical Agency estimates that the population of Addis Ababa is growing by $3.8 \%$ every year [18]. The total fertility rate in Addis Ababa is the lowest among all regions of Ethiopia. However, the in-migration is too large; make the population growth rate high. Because of the booming construction industry and other development schemes in the capital, people from the country-side often migrate to Addis Ababa.

\section{Study Design and Sampling}

We conducted a comparative cross-sectional study covering nine out of ten sub-cities of Addis Ababa in July 2017. All women of reproductive age living in Addis Ababa were the target population for the study. To locate the study population and conduct sampling without selection bias, we carried out household based sampling and drew representative samples of women aged 18 to 49 years who gave birth one year preceding the date of data collection. We used administrative borders to select study clusters. Woredas (districts) in Addis Ababa were sub-divided into smallest places called 'Ketenas' used by authorities to provide some of the public services in an effective way. Health Extension Workers (HEWs), for example, use these Ketenas to provide house-to-house services. Ketenas were further subdivided into smaller villages.

A three stage sampling technique was applied to select the households and ultimately, the study population. In each sub-city, the first step was to select study Ketenas using simple random sampling. The villages within the Ketenas were then identified, which led to the second stage of the sampling process.

Supported by Health Extension Workers (HEWs), we identified borders between all identified villages, and later selected the villages using simple random sampling for inclusion in the study. The selected villages were clustered, and to establish a sampling frame, household listing was carried out in each cluster. We sketched a map of the villages to avoid overlaps during household listing.

In the third stage, a fixed number of 20 households per cluster were selected with an equal probability random selection from the newly created household listing. All women aged 18-49 years who gave birth one-year preceding the date of data collection were invited to a face-to-face interview. If women in the selected household did not fulfil the eligibility criteria, the eligible household next to the selected 
household was included. Sample size was determined using the formula for comparative cross-sectional studies.

\section{Development and Testing of the Data Collection Tools}

A structured questionnaire was developed to measure a variety of variables, such as inequality in service delivery during pregnancy, labour and childbirth. While some of the questions were adapted from similar studies conducted in low-income countries in the past, most questions to estimate the variables were developed by the investigators after extensive literature review. The questions which were used to measure sociodemographic status and for variables related to pregnancy profile of study participants were adapted from the women's questionnaire of the Ethiopian Demographic and Health Survey.

The study tool development process passed through numerous steps to ensure its validity and reliability. The steps taken include: expert consultation, asking elder women from different backgrounds and, eventually, by conducting a pilot study to measure internal consistency and test the validity of the tool. We conducted a brief piloting in a place outside the study area with similar characteristics to the study area population with twenty women enrolled in the pilot. The tool was checked for clarity, whether participants understand the language and whether there is any sensitive words. We made revisions to the language and sequence of questions based on the findings of the pilot.

\section{Data Collection}

We recruited interviewers who had a college degree in health or social sciences to collect the data. To ensure that valid and reliable data are gathered or obtained, interviewers attended three-day data collection training, and were well versed on the questionnaire and interviewing techniques. Apart from this, the interviewers understood the language and culture of the study population.

Prior to the actual data collection was started, interviewers were provided with the exact location and sketch maps of the study clusters. The sketch map had the details of the location where the study cluster is found, including main landmarks in the area. The sketch map had also the details of marks of all structures found in the cluster, which helped the interviewer to accurately identify and select households. The interviewers were also assisted by village guiders to properly identify borders and landmarks of the study area.

Data collection was conducted using tablet computers. The questionnaire designed on tablet computers using "commcare", a web based data entry platform. The web based questionnaire was tested for user friendliness, and was programmed to avoid inaccurate entries, such as skipping responses when deemed necessary.

Interviewers approached all women aged 18 to 49 years in the selected household and checked for eligibility using a screening form. After identifying all eligible women in the household, interviewers asked for consent and conducted face-to-face interviews with those women who consented to participate in the study. In each eligible household, interviewers observed housing characteristics and availability of 
household items to estimate the wealth of the household. In households where women were not available in the first visit, interviewers conducted re-visits for a second time. Households missed during the second visit were assumed as non-response.

\section{Data Analysis}

Categorical socio-demographic and clinical characteristics of study participants were compared between women who received maternal health services and those women who did not use services using chisquare test. Bivariate analyses were conducted to estimate the crude regression coefficients and odds ratio (OR) of different potential risk factors that could be associated with coverage of maternal health services (Antenatal care, Delivery, post-partum care). Multiple linear regression analysis was conducted to compute adjusted coefficients, and logistic regression was used to estimate adjusted odds ratios. The coverage estimations were stratified by wealth, education, and employment status. STATA Version 14 (Stata Corp LLC, College station, Texas) was used to analyse the data.

\section{Results}

Table 1 shows sociodemographic characteristics of the study participants. More than eight out of ten participants were aged 20 to 34 years, while only one out of six participants was older than 34 years. About $34 \%$ of the participants attended primary education, while only $17.8 \%$ had attended tertiary education. Nine percent of participants did not attend education at all. The majority of participants $(89.1 \%)$ were married and living with their partners during the study.

Table 2 shows pregnancy history and ANC contacts for the recent pregnancy. Close to $46 \%$ of participants gave birth only once and less than two percent of participants had five or more births. More than $98 \%$ of participants had at least one ANC contact for their recent pregnancy. Among those who had antenatal contacts, the majority $(67.7 \%)$ attended antenatal care in health centres followed by private hospitals (16.1\%). More than $59 \%$ of participants had five or more antenatal contacts for their recent pregnancy. A little more than $90 \%$ of participants adhered to the recommended four or more ANC contacts. Only $59.3 \%$ of women adhered to the recommended contacts at the recommended stages of their pregnancy.

Table 3 shows place of delivery and the timing for post-partum care. More than $98.0 \%$ of participants gave birth in a health facility. Among those who gave birth in a health facility, $40.7 \%$ gave birth in a health centre while $35.8 \%$ gave birth in a public hospital. Almost one-fifth of the participants gave birth in a private-for-profit facility (either private clinic or hospital). The majority (80.5\%) of participants attended post-partum care within a week after childbirth. However, only $21.5 \%$ received post-partum care within two days after childbirth, the critical period for maternal and neonatal death.

Figure 1 shows the percentage of women who had all the recommended ANC contacts at the recommended time by household wealth quintile. The percentage of women who had all the recommended ANC contacts at the right time steadily increased as the wealth of the household 
increased. Less than $45.0 \%$ of women from the poorest households received all the recommended ANC contacts at the right time, while $71.4 \%$ of women from richest households received all the recommended contacts at the right time. Overall, women either in the fourth or fifth quintile were more likely to receive adequate ANC contacts than women in the first or second quintiles.

Table 4 shows the average gap in ANC coverage and wealth based inequality in coverage gaps of nine sub-cities in Addis Ababa. The average city-wide gap in ANC coverage was $40.7 \%$. Wealth contributed one third of the coverage gap (PAR\% $=29.9 \%)$. The largest coverage gap was observed at Nifas-silk Lafto sub-city with an overall ANC coverage gap of $50.0 \%$. Yet wealth contributed about $12.5 \%$ of the coverage gap, as the coverage gap in the richest quintile was also larger (43.8\%) in Nifas-silk than other sub-cities. The largest wealth based inequality in coverage gap was observed in Akaki-kality sub-city (PAR = 21.7 percentage points), followed by Lideta sub-city (19.6 percentage points). Wealth contributed $56 \%$ and $47.7 \%$ of the coverage gap in Lideta and Akaki-kality sub-city, respectively.

As Figure 2 depicts, the majority of women from poorest households gave birth at health centres (66.2\%), followed by public hospitals (30.9\%). Meanwhile, the largest proportion of women from richest households gave birth at private hospitals ( $46.1 \%)$, followed by public hospitals ( $16.1 \%)$. A little more than $68 \%$ of all deliveries from private for profit clinics and $59.2 \%$ of all deliveries from private hospitals were from richest households. Only $8.5 \%$ of deliveries at health centres were from richest households.

Table 5 shows that both maternal and partner education affected service use for antenatal care. As the education level of mothers and their partners increased, service use for ANC increased. In this study, only $52.5 \%$ of women with primary education had all the recommended ANC contacts, while $78.5 \%$ of women who completed tertiary education had all the recommended ANC contacts $(p<0.001)$. One out of two (49.3\%) women whose partner had some primary education had the full recommended ANC contacts, while three out of four $(75.1 \%)$ women whose partner completed tertiary education had the full recommended ANC contacts $(P<0.001)$.

\section{The Prevalence of Multiple Barriers to Access to Maternal and Newborn Health Service before and after Arrival to Healthcare Facilities}

As Figure 3 shows, higher proportion of uneducated (64.4\%) than educated (48.7\%) women encountered multiple barriers to access health services during pregnancy, childbirth and the postpartum period. Similarly, a higher proportion of unmarried (62.5\%) than married $(47.0 \%)$ women encountered multiple barriers. Three in five women aged less than 20 years encountered multiple barriers while one in two women aged 20 to 34 years encountered multiple barriers. A smaller proportion of women from richest (35.1\%) than poorest $(50.7 \%)$ households encountered multiple barriers to access health services during pregnancy, childbirth and the postpartum period. Overall, $50 \%$ of women encountered multiple barriers to access health services during their recent pregnancy.

Only a small proportion of women encountered multiple barriers before arrival at healthcare facilities to receive health services during pregnancy, childbirth and the postpartum period. As Figure 4 shows, almost 
none of the study participants encountered multiple barriers before arrival to healthcare facilities. More than $80 \%$ of women did not encounter even one barrier before arrival at healthcare facilities.

Figure 5 reveals the proportion of women who faced multiple barriers (two or more barriers) to use health services after arriving to healthcare facilities. A higher proportion of women aged below 20 years (60\%), uneducated women (59.3\%), and unmarried women (66.7\%) were more likely to encounter multiple barriers. On the other hand, a lower proportion of women from richest households (30.5\%) encountered multiple barriers than women from poorest households ( $47.8 \%$ ). Overall, about $45 \%$ of women encountered multiple barriers after arrival to healthcare facilities.

As Table 6 depicts, bivariate analysis revealed that women with primary or more education were less likely to face multiple barriers to receive care compared with women who did not have education (OR = $0.53, p=0.021)$. Moreover, women from richest households were less likely to face multiple barriers compared with women from poorest households $(O R=0.48, p=0.003)$. The association remained significant after adjusting for confounders both for educational level $(O R=0.54, p=0.049)$ and wealth $(\mathrm{OR}=0.57, \mathrm{p}=0.032)$.

\section{Discussion}

In this study, more than $90 \%$ of women reported that they had four or more ANC contacts during their recent pregnancy. However, further analysis of the data revealed that the timing for ANC attendance was not in line with WHO recommendations. Only $62.7 \%$ of women had ANC contact in the first trimester of pregnancy and $59.3 \%$ of women had all the recommended ANC contacts within the recommended time period. Past studies in low and middle-income countries also reported that ANC follow-up in the first trimester of pregnancy is a rare occurrence. Agha and Tappis [19] reported that only $48 \%$ of women in Pakistan had ANC contacts in the first trimester of pregnancy. Other researchers had also reported that low proportion of women starts ANC follow-up in the first trimester of pregnancy [20-24].

With regard to the level of inequality between women of different socio-economic status, less than $45.0 \%$ of women from poorest households received all the recommended ANC contacts within the recommended time while $71.4 \%$ of women from richest households had all the recommended contacts in the same period. The inequality in ANC use between women from richest and poorest households was consistently high across all sub-cities of Addis Ababa. Overall, wealth contributed for $29.9 \%$ of the ANC coverage gap in Addis Ababa. The ANC coverage gap in Addis Ababa, in part, stemmed from differences in wealth and education among households.

The wealth-based inequality in ANC use in low and middle-income countries is widely reported in the literature. Amin et al [25], for example, reported that the rate of ANC use is much lower among women from poorest households. Other researchers reported similar findings [26-30]. It has been well acknowledged in the literature that poor households are socially marginalised and in many ways, excluded from the social network, which is one of the powerful tools for disseminating knowledge about the betterment of health among the marginalised sections of society [31]. 
Apart from wealth, ANC coverage was significantly higher among educated than uneducated women. As the level of education increases, ANC service use increases steadily. The partner's education was also significantly associated with ANC service use. This finding is in line with previous reports in Ethiopia and other low-income countries. There are evidences showing that better basic education can, through general improvements in literacy and specific health knowledge, increase the desired and actual use of health services. Studies in many countries have, for example, indicated the importance of education on the timely use of health services and in improving health outcomes [17, 32-37].

The study revealed that institutional childbirth coverage was almost universal. More than $98 \%$ of women gave birth in a healthcare facility. Yet, with regard to the place of delivery, a higher disparity was noted between women from richest and poorest households. Women from richest households were more likely to give birth at higher level facilities with better technologies to detect complications at earlier stage, whereas women from the poorest households gave birth at lower level facilities. Similar findings were also reported from studies in other countries. The Jordan Demographic and Health survey reported, even though the coverage in skilled attendant delivery in Jourdan was almost universal (99\%), the majority of disadvantaged women gave birth at lower level healthcare facilities, while their richest counterparts gave birth at private hospitals with better diagnostic capabilities [38]

A national Emergency Obstetrics and Newborn Care (EmONC) survey conducted in Ethiopia in 2016 [39] revealed that a substantial number of lower level healthcare facilities are not in a position to provide standard care during labour, childbirth and in the postpartum period. In Addis Ababa, $82 \%$ of health centres that were designated as EmONC facilities were not in actual fact able to provide the recommended services [39]. Hence, even though institutional delivery was nearly universal in Addis Ababa, the majority of women from poorest households gave birth in a facility that provides only routine care. This calls for an unprecedented effort to improve the standard of care at lower level facilities. Unless the standard of care at lower level facilities improves, the poor will remain excluded from good quality labour and childbirth services and thus obstetric related deaths will continue to extend its toll.

Studies in other African countries reported that lower level facilities are not readily prepared to provide EmONC services. In a study conducted in dozens of Sub-Saharan Africa countries, researchers found that in half of the countries evaluated, most births actually occurred in facilities incapable of providing basic signal functions [40].

As this study revealed, women encountered two or more barriers to receive services after arriving than before arriving to healthcare facilities. Only few women reported that they encountered multiple barriers before arriving healthcare facilities while almost $50 \%$ of women reported that they encountered multiple barriers after arriving to healthcare facilities. This indicates that poor health system performance is yet the major barrier to access labour and childbirth services in Addis Ababa, especially for women of low socio-economic status. Perhaps, poor health system performance was reported as a barrier to access to key health interventions in many countries [40]. As the Commission on Social Determinants of Health 
(CSDH) pinpointed, the health system is part of the social determinates of health [41]. The CSDH noted that the health system is the intermediary factor on the social determinants of health inequalities.

\section{Conclusion}

There is a huge inequality in maternal healthcare coverage in Addis Ababa. Multiple barriers block women, especially women from poor households, to receiving care during pregnancy, childbirth and in the post-partum period. While some of the barriers lay outside of the healthcare system, the majority are embedded within the healthcare system. Women from lower socio-economic groups feel that they often receive unsatisfactory care. Women from lower socio-economic status also feel that the quality of healthcare service at public facilities, especially at health centres, is much lower than their expectations. To achieve universal maternal health coverage, affordability of the service is not adequate although it is one of the necessities. Other underlining social determinants deserve the attention of policy makers and program designers.

\section{Abbreviations}

ANC

Antenatal Care

CSDH

Commission on Social Determinants of Health

EmONC

Emergency Obstetrics and Newborn Care

HEWs

Health Extension Workers

SDG

Sustainable Development Goal

\section{Declarations}

\section{Ethics approval and consent to participate}

Ethical approval was obtained from the higher degrees committee of the Department of Health Studies at the University of South Africa and the Institutional Review Board (IRB) of the Addis Ababa Health Bureau, Ethiopia. All study participants gave written consent to participate in the study.

\section{Consent for publication}

Not applicable

\section{Availability of data and materials}


The datasets used and/or analysed during the current study are available from the corresponding author on reasonable request.

\section{Competing interests}

The authors declare that they have no competing interests

\section{Funding}

This study was funded by the University of South Africa. The University of South Africa has no role in the design of the study and collection, analysis, and interpretation of data and in writing the manuscript.

\section{Authors' contributions}

MY developed the study design and analysis plans, conducted the analysis and drafted the manuscript with revisions by PS. Both authors reviewed and approved the final manuscript writing.

\section{Acknowledgements}

Not applicable

\section{Authors' information}

Not applicable

\section{References}

1. Singh A. Supply-side barriers to maternal health care utilization at health sub-centers in India. PeerJ. 2016;4:e2675.

2. Byrne A, Hodge A, Jimenez-Soto E, Morgan A. Looking beyond supply: a systematic literature review of demand-side barriers to health service utilization in the mountains of Nepal. Asia Pacific Journal of Public Health. 2013;25:438-51.

3. Banerjee A, Bhawalkar J, Jadhav S, Rathod H, Khedkar D. Access to health services among slum dwellers in an industrial township and surrounding rural areas: a rapid epidemiological assessment. Journal of family medicine primary care. 2012;1:20.

4. O'Donnell $\mathrm{O}$. Access to health care in developing countries: breaking down demand side barriers. Cadernos de saude publica. 2007;23:2820-34.

5. Berg CJ, Callaghan WM, Syverson C, Henderson Z. Pregnancy-related mortality in the United States, 1998 to 2005. Obstetrics Gynecology. 2010;116:1302-9.

6. Peters DH, Garg A, Bloom G, Walker DG, Brieger WR, Hafizur Rahman M. Poverty and access to health care in developing countries. Ann N Y Acad Sci. 2008;1136:161-71. 
7. World Health Organization: World Health Statistics 2015. Geneva: World Health Organization; 2015. World health statistics 2016, 2012.

8. United Nations. Millennium development goals report 2014. New York: United Nations; 2014.

9. Barros AJ, Ronsmans C, Axelson H, Loaiza E, Bertoldi AD, França GV, Bryce J, Boerma JT, Victora CG. Equity in maternal, newborn, and child health interventions in Countdown to 2015: a retrospective review of survey data from 54 countries. The Lancet. 2012;379:1225-33.

10. United Nations. Transforming our world: The $\mathbf{2 0 3 0}$ agenda for sustainable development. New York: United Nations, Department of Economic and Social Affairs 2015.

11. World Health Organization. The World Health Report 2010: Health Systems Financing: the Path to Universal Coverage. World Health Organization 2010.

12. World Health Organization. Making fair choices on the path to universal health coverage: final report of the WHO Consultative Group on Equity and Universal Health Coverage. 2014.

13. Ottersen T, Norheim OF. Making fair choices on the path to universal health coverage. Bull World Health Organ. 2014;92:389.

14. Quick J, Jay J, Langer A. Improving women's health through universal health coverage. PLoS Med. 2014;11:e1001580.

15. Ministry of Health. Health and Health Related Indicators. Policy and Planning Directorate. Addis Ababa. 2018.

16. Central Statistical Agency [Ethiopia]. ICF: Ethiopia Demographic and Health Survey 2016: Key indicators report. Addis Ababa, Rockville: CSA and ICF 2016.

17. Mezmur M, Navaneetham K, Letamo G, Bariagaber $\mathrm{H}$. Individual, household and contextual factors associated with skilled delivery care in Ethiopia: Evidence from Ethiopian demographic and health surveys. PLoS One. 2017;12:e0184688.

18. Central Statistical Agency. Population Projection of Ethiopia for All Regions At Wereda Level. Addis Ababa; 2017.

19. Agha S, Tappis H. The timing of antenatal care initiation and the content of care in Sindh, Pakistan. BMC Pregnancy Childbirth. 2016;16:190.

20. Ejeta E, Dabsu R, Zewdie O, Merdassa E. Factors determining late antenatal care booking and the content of care among pregnant mother attending antenatal care services in East Wollega administrative zone, West Ethiopia. Pan African Medical Journal 2017, 27.

21. Yaya S, Bishwajit G, Ekholuenetale M, Shah V, Kadio B, Udenigwe O. Timing and adequate attendance of antenatal care visits among women in Ethiopia. PLoS One. 2017;12:e0184934.

22. Tesfaye G, Loxton D, Chojenta C, Semahegn A, Smith R. Delayed initiation of antenatal care and associated factors in Ethiopia: a systematic review and meta-analysis. Reproductive health. 2017;14:150.

23. Turyasiima M, Tugume R, Openy A, Ahairwomugisha E, Opio R, Ntunguka M, Mahulo N, Akera P, Odongo-Aginya E. Determinants of first antenatal care visit by pregnant women at community based 
education, research and service sites in Northern Uganda. East Afr Med J. 2014;91:317-22.

24. Kisuule I, Kaye DK, Najjuka F, Ssematimba SK, Arinda A, Nakitende G, Otim L. Timing and reasons for coming late for the first antenatal care visit by pregnant women at Mulago hospital, Kampala Uganda. BMC Pregnancy Childbirth. 2013;13:121.

25. Amin R, Shah NM, Becker S. Socioeconomic factors differentiating maternal and child health-seeking behavior in rural Bangladesh: A cross-sectional analysis. Int J Equity Health. 2010;9:9.

26. Mwase T, Brenner S, Mazalale J, Lohmann J, Hamadou S, Somda SM, Ridde V, De Allegri M. Inequities and their determinants in coverage of maternal health services in Burkina Faso. Int $\mathrm{J}$ Equity Health. 2018;17:58.

27. Yaya S, Uthman OA, Amouzou A, Ekholuenetale M, Bishwajit G. Inequalities in maternal health care utilization in Benin: a population based cross-sectional study. BMC Pregnancy Childbirth. 2018;18:194.

28. Saad-Haddad G, DeJong J, Terreri N, Restrepo-Méndez MC, Perin J, Vaz L, Newby H, Amouzou A, Barros AJ, Bryce J. Patterns and determinants of antenatal care utilization: analysis of national survey data in seven countdown countries. Journal of global health 2016, 6.

29. Joshi C, Torvaldsen S, Hodgson R, Hayen A. Factors associated with the use and quality of antenatal care in Nepal: a population-based study using the demographic and health survey data. BMC Pregnancy Childbirth. 2014;14:94.

30. Ahmed S, Creanga AA, Gillespie DG, Tsui AO. Economic status, education and empowerment: implications for maternal health service utilization in developing countries. PloS one. 2010;5:e11190.

31. Singh PK, Rai RK, Kumar C. Equity in maternal, newborn, and child health care coverage in India. Global health action. 2013;6:22217.

32. Tarekegn SM, Lieberman LS, Giedraitis V. Determinants of maternal health service utilization in Ethiopia: analysis of the 2011 Ethiopian Demographic and Health Survey. BMC Pregnancy Childbirth. 2014;14:161.

33. Greenaway ES, Leon J, Baker DP. Understanding the association between maternal education and use of health services in Ghana: exploring the role of health knowledge. J Biosoc Sci. 2012;44:73347.

34. Baker DP, Leon J, Smith Greenaway EG, Collins J, Movit M. The education effect on population health: a reassessment. Population development review. 2011;37:307-32.

35. Baker DP, Salinas D, Eslinger PJ. An envisioned bridge: Schooling as a neurocognitive developmental institution. Dev Cogn Neurosci. 2012;2:6-17.

36. Gakidou E, Cowling K, Lozano R, Murray CJ. Increased educational attainment and its effect on child mortality in 175 countries between 1970 and 2009: a systematic analysis. The Lancet. 2010;376:959-74.

37. Levine RA, Rowe ML. Maternal literacy and child health in less-developed countries: evidence, processes, and limitations. J Dev Behav Pediatr. 2009;30:340-9. 
38. Department of Statistics [Jordan]

Department of Statistics [Jordan]. International ICF: Jordan population and family health survey 2012. Department of Statistics and ICF International Calverton, MD; 2013.

39. Ethiopian Public Health Institute. Ethiopian Emergency Obstetric and Newborn Care (EmONC) Assessment 2016: Final Report. Addis Ababa: Ethiopian Public Health Institute. 2016.

40. Campbell OM, Calvert C, Testa A, Strehlow M, Benova L, Keyes E, Donnay F, Macleod D, Gabrysch S, Rong L. The scale, scope, coverage, and capability of childbirth care. The Lancet. 2016;388:2193208.

41. Solar O, Irwin A. A conceptual framework for action on the social determinants of health. 2010.

\section{Tables}

Table 1: Sociodemographic characteristics of study participants 


\begin{tabular}{|c|c|c|}
\hline Characteristic & Number & $\%$ \\
\hline \multicolumn{3}{|l|}{ Age group } \\
\hline$<20$ & 10 & 1.4 \\
\hline $20-34$ & 618 & 84.3 \\
\hline $35-49$ & 105 & 14.3 \\
\hline \multicolumn{3}{|l|}{ Ethnic group } \\
\hline Amhara & 388 & 52.5 \\
\hline Oromo & 166 & 22.4 \\
\hline Gurage & 87 & 11.8 \\
\hline Tigrawi & 59 & 8.0 \\
\hline Other** & 31 & 4.2 \\
\hline Refused to tell & 8 & 1.1 \\
\hline \multicolumn{3}{|l|}{ Main language at home } \\
\hline Amharic & 649 & 87.8 \\
\hline Oromifa & 46 & 6.2 \\
\hline Guragegna & 20 & 2.7 \\
\hline Tigregna & 14 & 1.9 \\
\hline Other* & 10 & 1.4 \\
\hline \multicolumn{3}{|l|}{ Educational status } \\
\hline None & 67 & 9.1 \\
\hline Primary & 255 & 34.6 \\
\hline Secondary & 233 & 31.6 \\
\hline Vocational & 49 & 6.6 \\
\hline Tertiary & 131 & 17.8 \\
\hline Refused & 2 & 0.3 \\
\hline \multicolumn{3}{|l|}{ Current religion } \\
\hline Ethiopian orthodox & 594 & 80.4 \\
\hline Protestant & 49 & 6.7 \\
\hline Muslim & 94 & 12.7 \\
\hline Other*** & 2 & 0.2 \\
\hline \multicolumn{3}{|l|}{ Current marital status } \\
\hline Married, living together & 614 & 89.1 \\
\hline Married, living apart & 42 & 6.1 \\
\hline Living with a male partner, not married & 15 & 2.2 \\
\hline Not married, living alone & 16 & 2.2 \\
\hline Don't know & 1 & 0.2 \\
\hline Refused & 1 & 0.2 \\
\hline \multicolumn{3}{|l|}{ Living in a condone? } \\
\hline Yes & 165 & 23.2 \\
\hline No & 547 & 76.8 \\
\hline
\end{tabular}

*Other includes Wolayita, Silte, Harari and Agew

**Includes Wolayita, Agew, Siltie, Gamo, Harari

Table 2: Pregnancy history and antenatal care contacts for recent pregnancy in Addis Ababa 


\begin{tabular}{|c|c|c|}
\hline Characteristic & Number & $\%$ \\
\hline \multicolumn{3}{|l|}{ Birth order } \\
\hline 1 & 339 & 45.9 \\
\hline 2 & 250 & 33.8 \\
\hline 3 & 114 & 15.4 \\
\hline 4 & 25 & 3.4 \\
\hline 5 or more & 11 & 1.5 \\
\hline \multicolumn{3}{|l|}{ Was your recent child wanted? } \\
\hline Yes & 656 & 88.9 \\
\hline No & 82 & 11.1 \\
\hline \multicolumn{3}{|c|}{ Participant had at least one ANC contact for a recent pregnancy } \\
\hline Yes & 726 & 98.2 \\
\hline No & 13 & 1.8 \\
\hline \multicolumn{3}{|c|}{ Type of healthcare facility for ANC attendance } \\
\hline Public hospital & 76 & 10.3 \\
\hline Private hospital & 119 & 16.1 \\
\hline Health centre & 500 & 67.7 \\
\hline Private clinic & 30 & 4.1 \\
\hline Private for non-profit clinic & 32 & 4.3 \\
\hline \multicolumn{3}{|c|}{ Timing of First ANC contact for recent pregnancy } \\
\hline First trimester & 455 & 62.7 \\
\hline Second trimester & 227 & 31.3 \\
\hline Third trimester & 15 & 2.0 \\
\hline I don't remember & 29 & 4.0 \\
\hline \multicolumn{3}{|c|}{ Total number of ANC contacts for the recent pregnancy } \\
\hline Once & 1 & 0.1 \\
\hline Two times & 15 & 2.1 \\
\hline Tree times & 35 & 4.8 \\
\hline Four times & 227 & 31.3 \\
\hline Five or more & 433 & 59.6 \\
\hline Don't remember & 15 & 2.1 \\
\hline \multicolumn{3}{|c|}{ Had all the recommended contacts at the recommended time } \\
\hline Yes & 438 & 59.3 \\
\hline No & 301 & 40.7 \\
\hline
\end{tabular}

Table 3: Place of delivery and timing of postpartum care in Addis Ababa 


\begin{tabular}{lcc}
\hline Characteristic & Number & $\%$ \\
\hline Place of delivery for the recent birth & & \\
\hline In a health facility & 727 & 98.4 \\
\hline Home & 12 & 1.6 \\
\hline Type of facility where the participant gave birth for the recent child & & \\
\hline Public Hospital & 260 & 35.8 \\
\hline Private Hospital & 120 & 16.5 \\
\hline Health Centre & 296 & 40.7 \\
\hline Private for profit clinic & 22 & 3.0 \\
\hline private for non-profit clinic & 29 & 4.0 \\
\hline Post-partum care attendance for a recent child & & \\
\hline Yes & 573 & 80.5 \\
\hline No & 139 & 19.5 \\
\hline Timing of post-partum attendance & & \\
\hline Within two days of childbirth & 123 & 21.5 \\
\hline After two days of childbirth & 450 & 78.5 \\
\hline
\end{tabular}

Table 4: Average gap in ANC coverage and wealth based inequality in ANC coverage gap in Addis Ababa

\begin{tabular}{|c|c|c|c|c|}
\hline \multirow[t]{2}{*}{ Sub-city } & \multicolumn{2}{|c|}{ Coverage gap } & \multirow[t]{2}{*}{ *PAR, percentage points } & \multirow[t]{2}{*}{ PAR \% $(95 \% \mathrm{CI})$} \\
\hline & Overall coverage gap & Gap in richest quintile & & \\
\hline Kirkos & 41.3 & 35.0 & 6.3 & 15.2 \\
\hline Yeka & 38.8 & 36.4 & 2.4 & 6.2 \\
\hline Arada & 42.5 & 24.4 & 18.1 & 42.6 \\
\hline Kolfe & 36.7 & 21.1 & 15.6 & 42.6 \\
\hline Gulele & 32.5 & 17.5 & 15.0 & 46.2 \\
\hline Lideta & 35.0 & 15.4 & 19.6 & 56.0 \\
\hline Akaki-kality & 45.6 & 23.8 & 21.7 & 47.7 \\
\hline Nifas-silk & 50.0 & 43.8 & 6.3 & 12.5 \\
\hline Bole & 42.5 & 35.3 & 7.2 & 16.9 \\
\hline Addis Ababa (overall)* & 40.7 & 28.6 & 12.2 & 29.9 \\
\hline
\end{tabular}

$* \mathrm{PAR}=$ Population attributable risk

Table 5: Education as a gradient in inequalities in ANC coverage in Addis Ababa 


\begin{tabular}{|c|c|c|c|c|c|}
\hline \multirow[t]{2}{*}{ Educational status } & \multicolumn{2}{|c|}{ Had the recommended ANC coverage } & \multicolumn{2}{|c|}{ Had no the recommended ANC Coverage } & \multirow[t]{2}{*}{ P-value* } \\
\hline & Number & $\%$ & Number & $\%$ & \\
\hline \multicolumn{6}{|c|}{ Educational status of the participant } \\
\hline No education & 1 & 14.3 & 6 & 85.7 & \\
\hline Some primary & 84 & 52.5 & 76 & 47.5 & \\
\hline Completed Primary & 51 & 53.7 & 44 & 46.3 & \\
\hline Some secondary & 55 & 70.5 & 23 & 29.5 & $<0.001$ \\
\hline Completed secondary & 100 & 64.5 & 55 & 35.5 & \\
\hline Vocational & 30 & 61.2 & 19 & 38.8 & \\
\hline Some tertiary & 22 & 57.9 & 16 & 42.1 & \\
\hline Completed Tertiary & 73 & 78.5 & 20 & 21.5 & \\
\hline \multicolumn{6}{|l|}{ Partner's educational status } \\
\hline No education & 0 & 0.0 & 2 & 100.0 & \\
\hline Some primary & 36 & 49.3 & 37 & 50.7 & \\
\hline Completed Primary & 31 & 40.8 & 45 & 59.2 & \\
\hline Some secondary & 39 & 60.0 & 26 & 40.0 & $<0.001$ \\
\hline Completed secondary & 115 & 59.9 & 77 & 40.1 & \\
\hline Vocational & 22 & 64.7 & 12 & 35.3 & \\
\hline Some tertiary & 12 & 52.2 & 11 & 47.8 & \\
\hline Completed Tertiary & 130 & 75.1 & 43 & 24.9 & \\
\hline
\end{tabular}

* P-value calculated using Pearson Chi-square

Table 6: Factors associated with multiple barriers to access health services during pregnancy, childbirth and the postpartum period 


\begin{tabular}{|c|c|c|c|c|}
\hline Characteristic & $\begin{array}{c}\text { Crude OR } \\
(95 \% \text { CI) }\end{array}$ & P-value & $\begin{array}{l}\text { Adjusted OR } \\
\qquad(95 \% \mathrm{CI})\end{array}$ & P-value \\
\hline \multicolumn{5}{|l|}{ Age group } \\
\hline$<20$ & ref & & & \\
\hline $20-34$ & $0.65(0.18,2.31)$ & 0.501 & & \\
\hline $35-49$ & $0.73(0.20,2.75)$ & 0.646 & & \\
\hline \multicolumn{5}{|l|}{ Education } \\
\hline No education & ref & & & \\
\hline Primary or above & $0.52(0.30,0.91)$ & 0.022 & $0.50(0.27,0.95)$ & 0.035 \\
\hline \multicolumn{5}{|l|}{ Religion } \\
\hline Ethiopian orthodox & ref & & & \\
\hline Protestant & $1.18(0.66,2.11)$ & 0.584 & & \\
\hline Muslim & $1.29(0.83,2.00)$ & 0.255 & & \\
\hline \multicolumn{5}{|l|}{ Marital status } \\
\hline Married, living together & ref & & & \\
\hline Married, living apart & $1.20(0.64,2.24)$ & 0.573 & $1.11(0.59,2.10)$ & 0.743 \\
\hline Living with partner, not married & $2.18(0.74,6.44)$ & 0.160 & $2.17(0.72,6.60)$ & 0.170 \\
\hline Not married, living alone & $1.81(0.65,5.05)$ & 0.255 & $1.68(0.59,4.76)$ & 0.329 \\
\hline \multicolumn{5}{|l|}{ Birth order } \\
\hline One & ref & & & \\
\hline Two & $1.08(0.78,1.49)$ & 0.660 & & \\
\hline Three & $1.04(0.68,1.59)$ & 0.849 & & \\
\hline Four & $1.13(0.50,2.55)$ & 0.770 & & \\
\hline Five or more & $1.25(0.37,4.18)$ & 0.716 & & \\
\hline \multicolumn{5}{|l|}{ Wealth Quintile } \\
\hline Lowest & ref & & & \\
\hline Second & $1.14(0.72,1.81)$ & 0.583 & $1.20(0.73,1.96)$ & 0.476 \\
\hline Middle & $1.26(0.79,2.02)$ & 0.326 & $1.29(0.78,2.14)$ & 0.328 \\
\hline Fourth & $1.14(0.72,1.81)$ & 0.578 & $1.25(0.76,2.06)$ & 0.375 \\
\hline Highest & $0.52(0.33,0.84)$ & 0.007 & $0.63(0.38,1.05)$ & 0.075 \\
\hline
\end{tabular}

\section{Figures}




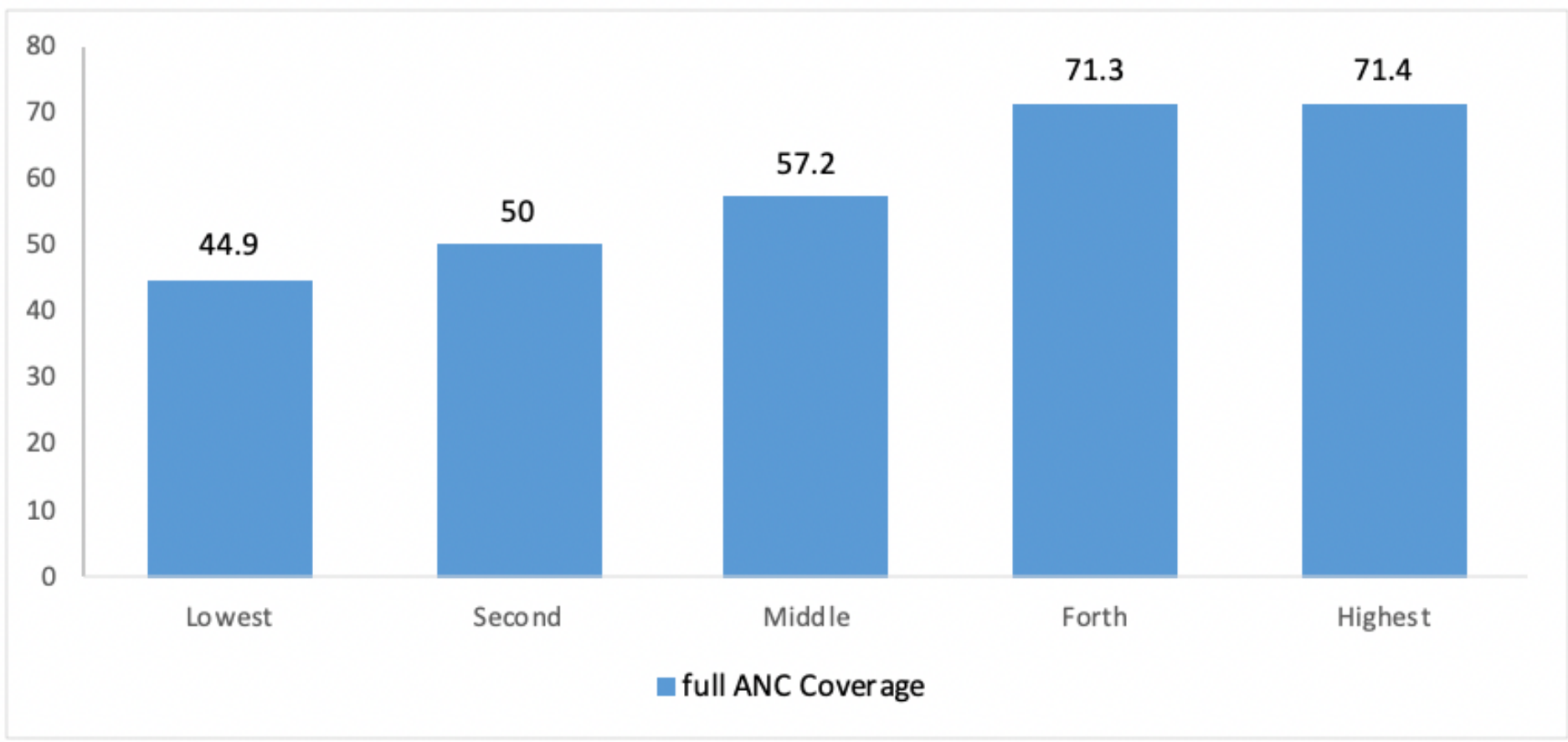

\section{Figure 1}

Percentage of women with the recommended ANC contacts at the recommended time by household wealth

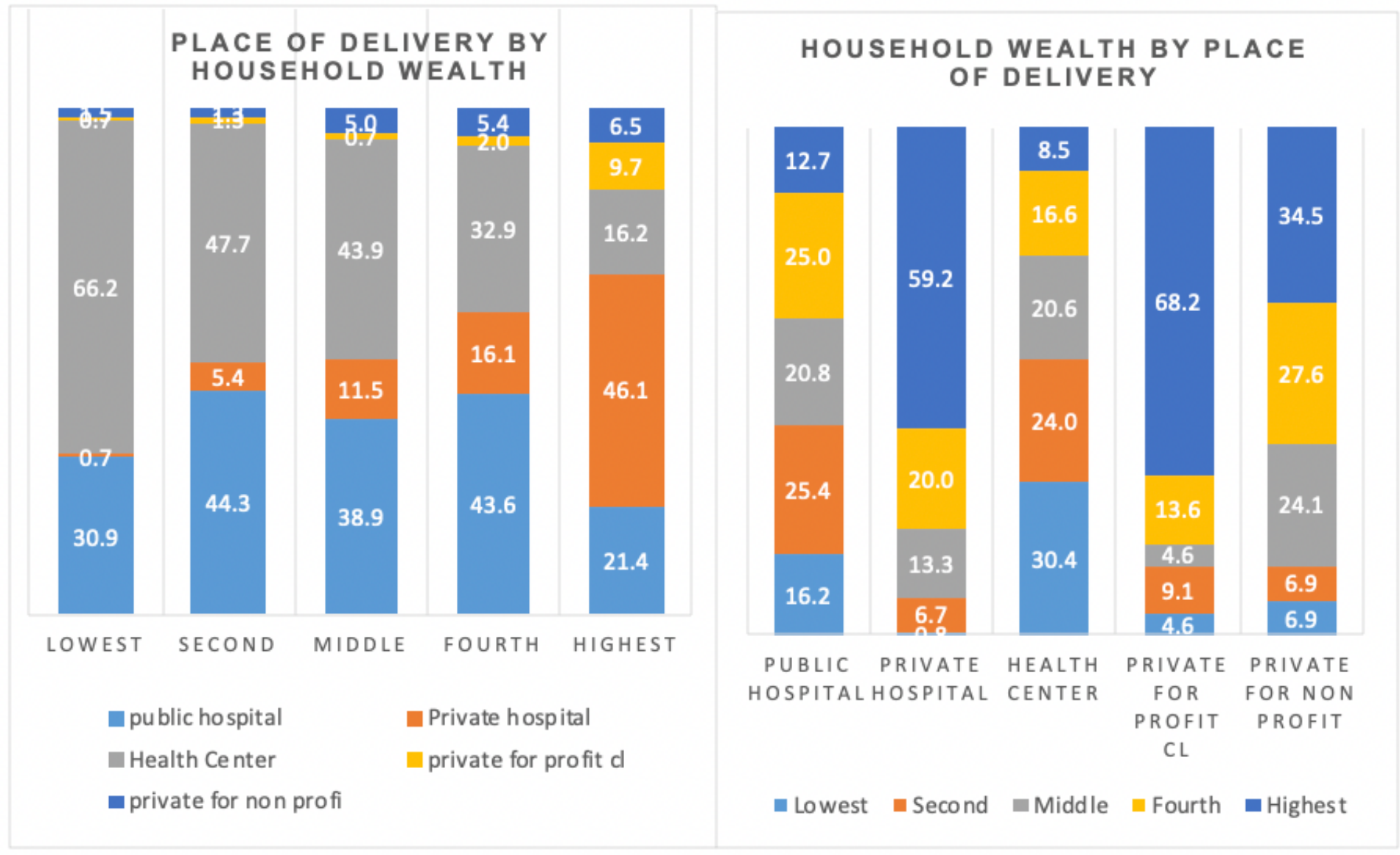


Figure 2

Place of recent delivery in Addis Ababa by household wealth, and household wealth by place of delivery

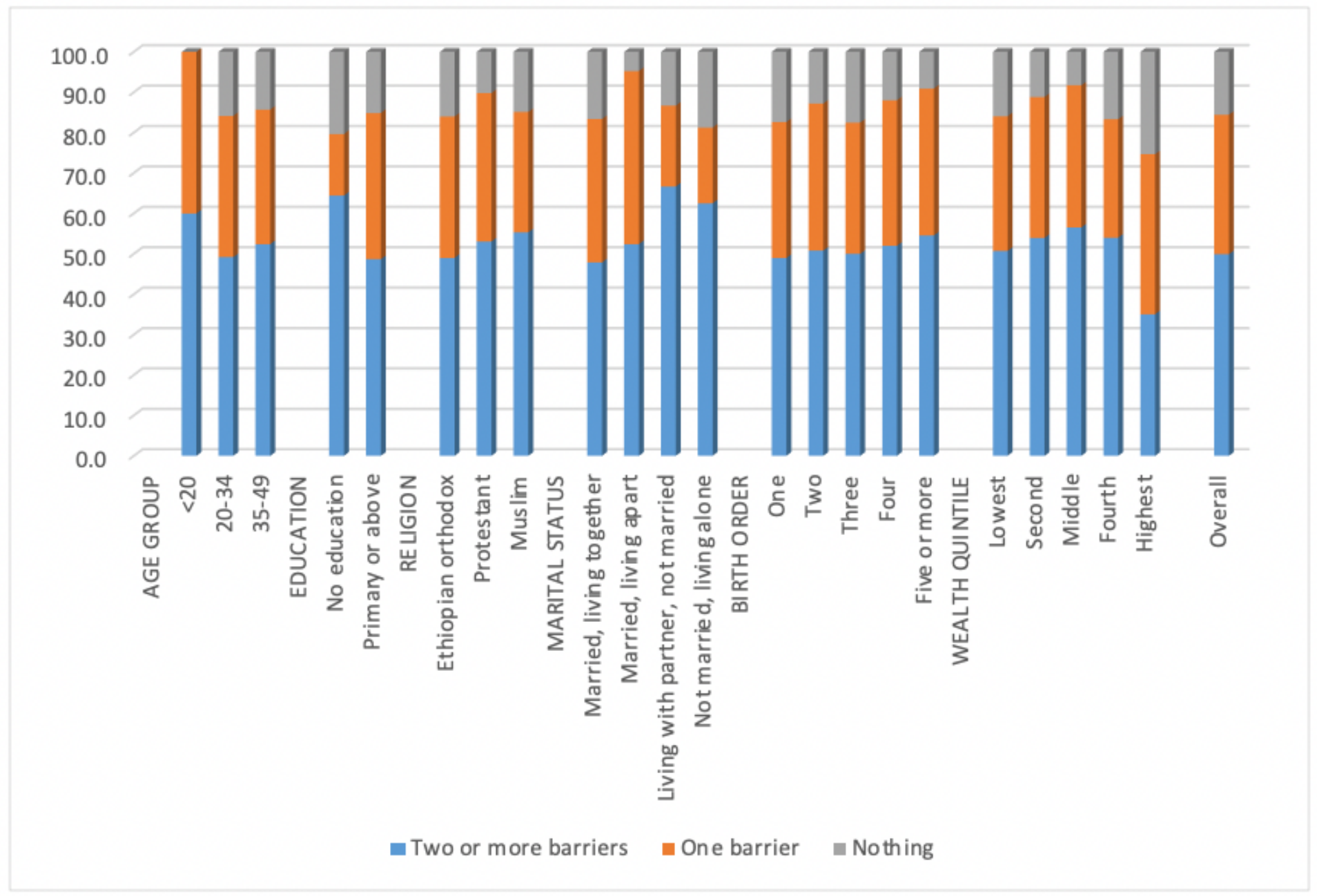

Figure 3

Percept of women who encountered multiple barriers to access health services during pregnancy, childbirth and the post-partum period 


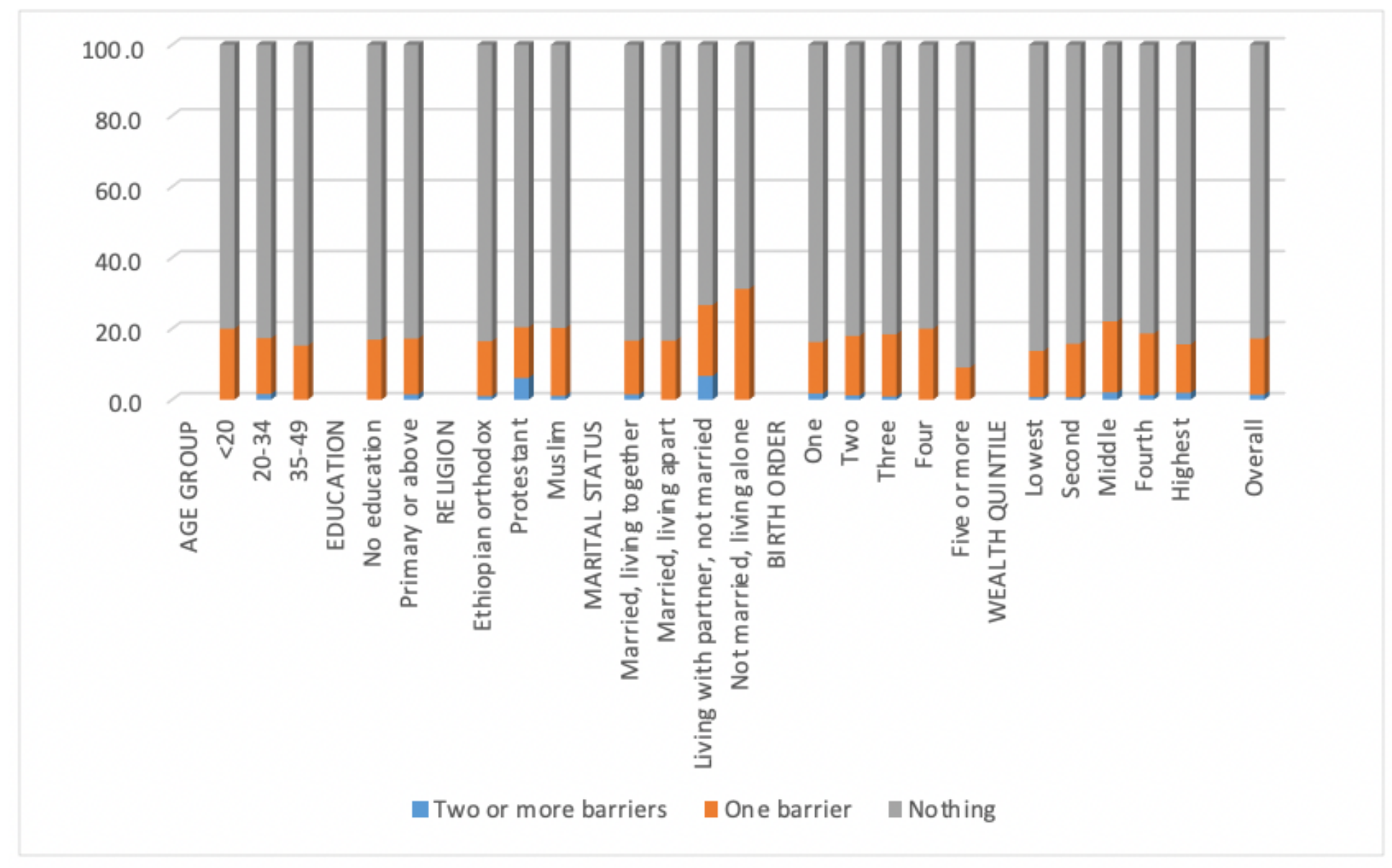

Figure 4

Percept of women who encountered multiple barriers to access services before arrival at a healthcare facility 


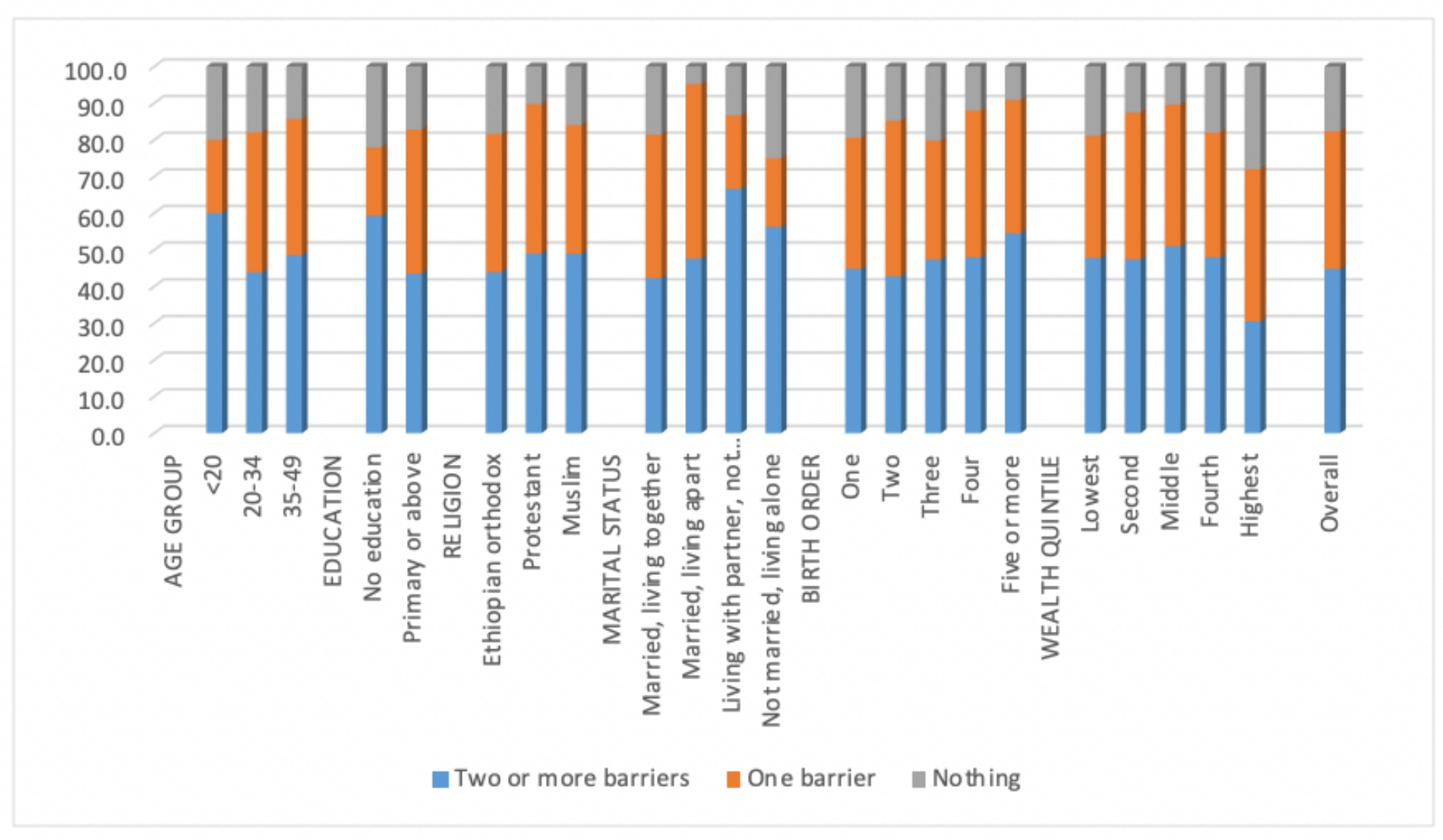

\section{Figure 5}

Percept of women who encountered multiple barriers to access health services after arrival at healthcare facilities 